\title{
CONTENT ANALYSIS OF JOB ADVERTISEMENTS FOR IDENTIFYING EMPLOYABILITY SKILLS
}

\author{
Ivona Lipovac and Marina Bagić Babac*
}

University of Zagreb, Faculty of Electrical Engineering and Computing

Zagreb, Croatia

DOI: $10.7906 /$ indecs.19.4.5

Regular article

Received: 16 August 2021. Accepted: 26 November 2021.

\begin{abstract}
Recently, web-based job sites appear to be the major source of advertisements. However, it has been argued that search engine toolkits restrict wording used to find job skill requirements, which requires clearly defined commonly used terms. This article aims to analyse 16000 online job advertisements using content analysis to identify current skills required by various professions in order to allow the comparison across countries through time to identify if trends vary in different national markets. In addition, algorithmic approaches to processing data were used to collect, sift, and organize content as well as to improve the efficiency and reliability of the analysis, and to derive a conceptual model of practitioner knowledge, skills, and abilities. Useful insights were given about the skills that employers require, based on online job advertisements from the USA, UK, Ireland, and Hong Kong.
\end{abstract}

\section{KEY WORDS}

content analysis, job advertisements, workforce skills

\section{CLASSIFICATION}

JEL: $\quad$ J23, J24 


\section{INTRODUCTION}

The labour market is extensive and exposed to constant changes due to globalization, development of technology and science, changes in the demographic structure and environment. It is important to know labour market, its trends, employers' requirements, for an individual to easier and better prepare for the desired job.

The research which uses job advertisements as data are growing in popularity in the new era. This type of research provides useful insight into the labour market and gives an opportunity to understand working conditions, salaries, and occupational changes. A major motivation for these kinds of studies is to examine the changing nature of skills that are required in the workplace. A development like this could enable more collaboration between researchers and recruiting organisations resulting in major benefits for both recruiters and individuals seeking for the job [1].

In the study conducted by Maier et al. [2], the researchers discovered that the number and variety of technical skills mentioned in job ads were increasing over the time examined. This indicates that the desired skills of employees are evolving over time, so knowing employers' requirements helps individuals to remain competent. In addition to the facts stated above, knowing labour market, and required skills are not only important for individuals seeking for the job, but also for policymakers in the areas of education and training, career guidance, labour market activation, immigration, and enterprise development, employers, HR consultants and recruiters [3].

The primary goal of this article is to provide trends into employment and workforce skills as such indicators can help to influence rising educational attainment, technologic convergence, and demographic change. In addition, these trends indicate skill shortages, consumer demand, and changing industrial structure. Therefore, a content analysis of job advertisements is used to identify current skills required by various professions in order to allow the comparison across countries through time to identify if trends vary in different national markets.

This article is organized into four major sections. Related research is reviewed in the introductory section. The following section describes the methods and necessary preparations made before the analysis itself. Finally, the results achieved through the content analysis are presented and discussed, with several conclusions drawn.

\section{RELATED WORK}

A primary goal motivating the content analysis of job advertisements in numerous research studies has been to derive a conceptual model of employees' knowledge, skills, and abilities [3]. From the study by Maier and Clark [2], it is noticeable that this kind of research is not so new, indicating how job advertisements were analysed across different decades.

Using content analysis of online job advertisements from Monster.com, Backhaus [4] argues that differences exist among companies in recruitment tactics. For instance, certain companies focus on company branding rather than on employee benefits. Baravalle and Capiluppi [5] used the same website in their research as Backhaus. They focused on job advertisements in IT sector and discovered a very common problem of mismatch between requirements of UK industry and offer of educational and training institutions.

To derive trends in programming skills, Smith, and Ali [6] examined job advertisements from online job agency www.dice.com. Their approach included extracting key terms from over 80000 job advertisements. The Dice platform was also used in research by Surakka [7] with similar motivation for research as Smith and Ali [6], reporting that the duties of software developers changed as technically more versatile, that it is no longer enough to have skills only in one or 
two programming languages. Molinero and Xie [8] presented key groups of skills in online job advertisements using cluster analysis in combination with multi-dimensional scaling.

Lee and Lee [9] gathered job advertisements from websites of companies featured in Fortune 500. The focus of their research was on job advertisements for IT managers. The outcomes of the research indicate that IT job applicants with high school diplomas or associate degrees possibly would not become IT managers in these companies because these companies do not appreciate the value of certification but strongly require their IT managers to possess technical skills and system skills, as well as business skills.

Furthermore, Dörfler and Werfhorst [10] focused on skills that employers require in various occupations. The outcome of their research is that employers require a wider set of skills over time, including not only occupational skills but also social and personal skills. A similar conclusion was presented in research by Kureková, Beblavý, and Thum-Thysen [11]. Using content analysis and simple statistical methods, they explored the Slovak labour market and found that employers in Slovakia are fairly demanding a wide set of skills even in formally low-skilled jobs. Using text mining on publicly available job advertisements, Pejić Bach [12] performed research related to analysis of competencies required in Industry 4.0 to develop a profile of Industry 4.0 job advertisements. However, Bennett [13] argues that the problem with skills employers' demand is that usually the level of competence for each skill is not defined, which leads to problems where universities do not know what to teach and candidates do not know exactly what they are being asked to demonstrate. Thus, Bennett suggests that organisations create a uniform set of short, straightforward, and easily memorable definitions of key skills to facilitate shared understanding.

Several research studies focused on exploring the quality of online job advertisements as a data source. Kureková, Beblavý, and Thum-Thysen [11] suggested strategies for overcoming selected methodological issues and that online job advertisements can be coupled with other sources of vacancy data or text describing analysed professions. One of the goals of the research by Wade and Parent [14] was to determine how the required skill mix and the degree to which subjective assessments of the possession of skills affect the job performance. Also, researching online job advertisements to identify the mix of desired skills is very useful and can be exploited as valuable input to student counselling services or curriculum development. In addition, Huang [15] points out that the online job advertisements list a wider mix of skills, while practitioner literature tends to focus on technical skills.

There are numerous research studies conducted as a tool for improving education, training, and performance management such as a study by Iyer [16] used a content analysis of 394 job announcements in the visual resources field to improve education and training by providing the library community with the information necessary to support the development of programs for visual resource professionals. Another research with a similar purpose was the one by Payne [17]. The study examined Information Management (IM) within the UK through the comparison of content analyses of IM course curricula and IM job advertisements to determine what is recognised as the discipline of IM through the consideration of what components are taught within UK Higher Education Information Management degree curricula. Reeves and Hahn [18] also highlight the fact that the content analysis of job advertisements can inform curriculum development and enhancement, academic advising, and job-seeking implications for new graduates. They also suggest that these kinds of studies are needed all the time to reflect the current state of the labour market. The results of the previously mentioned research by Surakka [7] indicate that if the number of required skills for computer science graduates continues to increase, degree programs might have severe difficulties in following this change. In addition, Krstić [19] performed research on big data 
analysis to bring valuable business insights in the financial industry, indicating that methods can be used for any other domain to extract information. Moreover, the outcomes of these research studies are used for improving curricula, training, and performance management.

\section{RESEARCH METHODOLOGY}

\section{DATA COLLECTION}

The first step in collecting data is to select the relevant source of job advertisements. Here, Indeed, an American worldwide employment-related search engine for job listings was used [20]. Such websites offer a low cost of posting job advertisements which enables the employers to post more detailed descriptions of their requirements [21]. For the purposes of this study, 16 cities with the most numerous job advertisements were collected. Most of them are from the USA, several from the UK, and one city from Ireland and China. Thus, around a thousand job advertisements were collected for every city, over the period from January $19^{\text {th }} 2020$ to March $23^{\text {rd }} 2020$.

\section{CONTENT ANALYSIS}

Content analysis is a research method for studying documents and communication artifacts, which might be texts of various formats, figures, audio, or video used to examine patterns in communication in a replicable and systematic manner [22-24]. There are numerous examples of research based on content analysis that shows how text mining is used in various areas [25, 26]. A key element of content analysis is to code data in a way that will categorize it [27]. To accomplish this, the content analysis uses variables to represent the counts or proportions of keywords encountered within the records of text [28]. Using content analysis, four key parts of job advertisement are analysed: Job Title, Company, Job Description, and Salary. Figure 1 illustrates the process of data collection, content analysis, and presentation of the results.

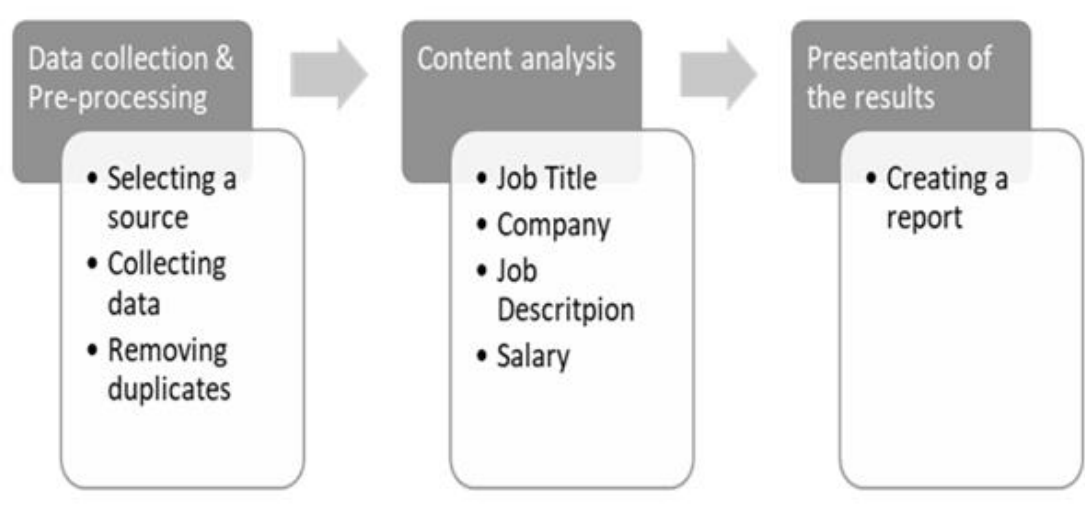

Figure 1. The process of data collection, content analysis and results presentation.

\section{RESULTS}

\section{JOB TITLE ANALYSIS}

According to UK Office for National Statistics, during the period from January to March 2020, the number of vacancies in professional, scientific, and technical activities, administrative and support service activities, accommodation and food services, human health, and social work, as well as in wholesale and retail trade increased significantly [29]. From Table 1, it is 
evident for Birmingham, Manchester, Edinburgh, and London that these facts are confirmed for the majority of sectors. The vacancies are most numerous in administrative and support service activities. On the other hand, vacancies in professional, scientific, and technical activities are represented but to a much lesser extent than projected.

Table 1. Frequencies of job vacancies in the cities worldwide that appeared on Indeed from January $19^{\text {th }}, 2020$, to March $23^{\text {rd }}, 2020$ (continued on p.516).

\begin{tabular}{|c|c|c|c|c|c|c|c|c|c|c|}
\hline \multirow{2}{*}{ Vacancy } & \multicolumn{10}{|c|}{ Cities* } \\
\hline & Bir & Man & Edi & Lon & Dub & NY & LV & Bos & SF & $\mathrm{HK}$ \\
\hline Administrator & 66 & 72 & 60 & 54 & & & & & & 9 \\
\hline Administrative Assistant & 17 & 30 & 11 & 30 & 8 & 27 & 10 & 3 & & 20 \\
\hline Analyst Operations & & & & & 5 & & & & & \\
\hline Advisor & & & & & & 10 & & 2 & & \\
\hline Business Analyst & & & & & 3 & & & & 3 & 10 \\
\hline Buyer & & & & & 6 & & & & 3 & \\
\hline Cashier & & & & & & 10 & 28 & 7 & & \\
\hline Cleaner & 15 & 11 & 14 & & 5 & 15 & & & & \\
\hline Collections Specialist & & & & & 3 & & & & & \\
\hline Compliance Analyst & & & & & 4 & & & & & \\
\hline Content Review Associate & & & & & 8 & & & & & \\
\hline Consultant & & & & & & 13 & 12 & & & 12 \\
\hline Customer Adviser & 20 & & 14 & 12 & 4 & & & & & \\
\hline Customer Assistant & 23 & 18 & 14 & 33 & & & & & & \\
\hline Customer Care & & & & & 3 & & & & & \\
\hline Customer Service & 13 & & 38 & & & & & & & \\
\hline Customer Specialist & & & & & 3 & & & 2 & & \\
\hline Customer Support & & & & & 3 & & & & & \\
\hline Data Analyst & & & & & 6 & & & & 7 & 3 \\
\hline Delivery Driver & & & 14 & & 4 & & & & & \\
\hline Designer & & & 13 & & 3 & & & 2 & & 5 \\
\hline Development Representative & & & & & 3 & & & & & 3 \\
\hline Director of Digital Sales & & & & & 3 & & & & & \\
\hline Dishwasher & & & & & 20 & & & 3 & & \\
\hline Executive Assistant & & & & & 5 & & & & & 9 \\
\hline Finance Associate & & & & & & & & & 4 & \\
\hline Floor Assistant & & & & & 3 & 20 & & 2 & & \\
\hline Graphic Designer & & & & & & & & 5 & 8 & 3 \\
\hline Housekeeper & & & & & & & 14 & & & \\
\hline HR Assistant & & & & & & 12 & & & & \\
\hline Investigator & & & & & & 22 & & 2 & 9 & \\
\hline Makeup Artist & & & & & 3 & & & & & \\
\hline Operations Assistant & & & & & & & & & 12 & 11 \\
\hline Personal Assistant & & & & 14 & & & & & & \\
\hline Porter & & & & & & & 12 & 2 & 4 & \\
\hline Receptionist & & & & & & 23 & 14 & & & 12 \\
\hline Retail Assistant & & & & & 3 & & 12 & & 7 & \\
\hline Sales Advisor & & & & & 3 & & 48 & & & 5 \\
\hline Sales Assistant & & 18 & & 18 & & 15 & & & & \\
\hline Sales Associate & 17 & 12 & & 10 & 6 & & 14 & & 5 & \\
\hline
\end{tabular}


Table 1. Frequencies of job vacancies in the cities worldwide that appeared on Indeed from January $19^{\text {th }}, 2020$, to March $23^{\text {rd }}, 2020$ (continuation from p.515).

\begin{tabular}{|c|c|c|c|c|c|c|c|c|c|c|}
\hline Secretary Assistant & & & & & 3 & & & 7 & & \\
\hline Security Officer & & & & & & & 16 & 2 & 8 & \\
\hline Services Representative & & & & & & & 10 & & 7 & \\
\hline Settlements Analyst & & & & & 3 & & & & & \\
\hline Software Developer & & & & & 4 & & & & & \\
\hline Software Engineer & & & & & 5 & & & & 3 & \\
\hline Support Officer & & 10 & & 10 & & & & & & \\
\hline Support Worker & & 10 & 33 & & & & & & & \\
\hline Teacher & & & & & & & 12 & & 3 & 8 \\
\hline Technical Support & & & & & 6 & & & & 3 & \\
\hline Transporter & & & & & & 10 & & & & \\
\hline Warehouse Operative & 14 & & 11 & & & & 12 & & 3 & \\
\hline
\end{tabular}

*Bir - Birmingham, Man - Manchester, Edi - Edinburgh, Lon - London, Dub - Dublin, NY - New York, LV - Las Vegas, Bos - Boston, SF - San Francisco, HK - Hong Kong

Recently, it was estimated that demand for occupations in professional, real estate, scientific and technical activities would see an increase by 425000 jobs by 2041 [8]. Information and communication, and education, health, and social work, and support service activities are also expected to increase in vacancies. Administrative and secretarial occupations are the only occupation group expected to see a London-wide decline in demand [30]. However, these predictions seem not quite accurate, although there is still a large period left to see if demand for administrative occupations will decrease as it is expected. These results only indicate that vacancies for the observed occupations were formally published. The demand for occupations from other mentioned sectors might also be high despite obtained results as employers may use other ways to fill the vacancies.

For Dublin, Ireland, the only sector with a marked increase in job vacancies since 2008 has been in professional, scientific, and technical activities [31]. Occupations like software developer, data analyst, and software engineer confirm that demand in this sector exists. Job vacancy rate in administrative and support activities, accommodation and food activities, information and communication and education activities stagnates during the last two years [31].

The US Bureau of Labor Statistics made a projection of trends in the labour market for the period 2018 to 2028. A slight increase in job vacancies is expected in the service-providing sector. However, sectors that are expected to see the fastest employment growth are health care and social assistance, private educational services, and construction. An increase in job vacancies is also expected in computer and mathematics and in renewable energy fields. On the other hand, several sectors are expected to see a decline in employment: retail trade, wholesale trade, utilities, the federal government, and manufacturing. A reason behind a decline in employment in retail trade is a shift to e-commerce [32]. This might also contribute to decreasing in job vacancies for the transportation and warehousing sector as well.

For New York, the most represented occupations are from the service-providing sector, as was expected. However, there are several deviations from the facts presented by the US Bureau of Labor Statistics. Occupations in transportation, retail trade, and wholesale sector are still among the most frequent vacancies which might indicate that the more significant decline in employment in these sectors has not occurred yet [33]. It is also noticeable that occupations such as administrative assistants are constantly in demand.

In Las Vegas, tourism is the biggest industry in Las Vegas and the major source of income. Therefore, the highest demand is expected to be in the service-providing sector. The results of 
the analysis confirm these expectations, showing that most of the most frequent vacancies are exactly in the service-providing sector. Furthermore, the occupations in administrative activities, are in much less demand considering previously analysed cities.

For Boston, occupations that occur more than ten times are still mostly from the service-providing sector. However, occupations such as illustrator, copywriter, graphic designer, videographer, and animator are also represented which leads to the conclusion that the occupations of the creative industry are high in demand in Boston. As was the case in most previous examples, occupations in administration are rich in vacancies.

For San Francisco, the distribution of vacancies by sectors is much more diverse than in other cities. Job vacancies indicate that occupations in information technology, marketing, sales, science, engineering, and business management are in demand.

Overall, the results from Table 1 confirm that similar trends were identified in the USA as well as in the UK and Ireland. The most announced occupations are in administration and service-providing activities. The example of Las Vegas shows that demand is higher for the occupations in the industry which city is known for. Although a large increase in employment in healthcare, science, technology, and engineering is projected, occupations in these industries are not so represented in given results which might implicate that there are other ways of finding employees for the positions in these industries.

For Hong Kong, the most common vacancies are in consultancy, finance, and administration. Also, Hong Kong has a high demand for administrative assistants, which is a trend that was already seen in the USA, Ireland, and the UK. Occupations such as designer, graphic designer, and copywriter suggest that growing demand for professionals in the multimedia and creative industry exists. Also, vacancies for teachers appeared as projected. Language teachers and skill teachers like coaches are the most sought-after occupations of this type in Hong Kong [34].

\section{ANALYSIS OF THE EMPLOYERS}

The most common employer in the UK is NHS Scotland, which occurred in 72 job advertisements. According to the Office for National Statistics, NHS Scotland is a public sector body, and it is among the top 10 largest public sector employers in the United Kingdom. Other public bodies listed above are the University of Manchester, Manchester University NHS Foundation Trust, and the University of Edinburgh. In addition, public listed companies in the retail sector such as Tesco, boohoo.com, and Morrisons are also among the most common employers. The private company Iceland also belongs to the retail sector. It should be also noted that several recruitment companies are among the most common employers, such as Pertemps Network Group, Page Personnel, and Web2Recruit. All these companies are private. Finally, Sykes is another public company specialized in customer service and technical support. To summarize, different types of employers use the website Indeed for finding employees who will fill job vacancies. Mostly public sector bodies and public listed companies. Private listed companies are slightly less common among employers. There are also examples of charitable sector organizations such as The Action Group from Edinburgh. The public sector bodies are mainly from the health and education sector. Also, most of the employers are from the retail sector which confirms the growing demand for occupations in retail trade and wholesale.

The results of the Dublin job vacancy analysis suggested a growing demand for occupations in professional, scientific, and technological industries, so IT and technology companies are expected to be among the most common employers. IT companies such as Facebook, Google, Accenture, Salesforce, and Microsoft are in the top 10 most represented employers. It should be noted that the most represented IT companies are American. However, Accenture is an 
example of an Irish company and according to Forbes magazine, it is in the top four largest companies in Ireland. As was the case with the UK, recruitment agencies in Ireland also use Indeed for finding employees. The Hays company is an example of a recruitment agency. On the other hand, public sector bodies are not among the most represented employers on Indeed for Ireland. The only example of a government agency is a Health Service Executive from the healthcare sector. Another issue that suggests that labour market in Ireland is slightly different than the one in the UK is that employers from the retail trade sector are also a lot less represented among the most common employers. The only example here is the supermarket chain SuperValu. Lastly, there are examples of pharmaceutical companies such as Novartis, companies specialized in investment banking such as CITI, telecommunications companies such as 3 Ireland, and management consulting company Deloitte. To conclude, the analysis of the employers in Dublin confirmed several previously derived conclusions such as the growing demand for occupations in the technology industry as well as a more diverse structure of the labour market than in the UK. It is important to mention that this analysis covers only Dublin therefore, the situation in the whole of Ireland might be different.

The United States Federal Government is the biggest employer in the USA since six out of ten most represented employers are from the public sector and are funded by the USA government. Similar trends found in the UK are repeated in the US, where universities are among the most common employers. However, unlike the UK where the employers from the retail sector are highly represented in the top ten most common employers, Nordstrom is the only example of the retail industry in the top ten most represented employers. Furthermore, NBCUniversal and Marriott International are examples of the entertainment and hospitality industry, which were not represented in the previously observed countries. Also, unlike Ireland, IT companies are much less represented, with only one example, Apple. It is important to add that the second largest employer in the USA, Walmart, occurs in only three job advertisements. One of the possible reasons might be that Walmart is using different platforms for announcing job vacancies.

To sum up, most of the employers in the USA belong to the public sector bodies, especially to the education sector. Other employers belong to various industries, from hospitality and technology to the media and retail industry. The results showed that employers from various industries use Indeed to announce job vacancies. On the other hand, some of the largest employers in the USA were not found among the most represented employers such as Walmart or Kruger which might suggest that there are other popular platforms besides which are used by these companies or there are other ways of finding employees.

Unlike other observed cities, most of the employers in Hong Kong are private companies. The single example of the public sector among the most common employers, the Hong Kong Productivity Council, may lead to the conclusion that Indeed is not a primary platform for announcing job vacancies in the public sector in Hong Kong. Furthermore, Earth.org is an example of a non-government organization that provides a scientific understanding of climate change and promotes environmental protection. As was the case in the UK, recruitment companies are among the most common employers on Indeed. Examples of the recruitment companies in the Table above are Classy Wheeler and Zebra Strategic Outsource Solutions. Companies specialized in logistics are Asia Airfreight Terminal and Cathy Pacific Services. Employers from the financial services and banking industry are highly represented. HSBC, CITI, Standard Chartered, and China CITIC Bank International are examples that illustrate the previous point best. Lastly, ITCS Group is an example of the IT industry which is the most represented in job advertisements. Thus, most of the employers presented on Indeed are private companies from the financial services and banking industry. Employers from the retail sector are not among the most common employers as was the case in the UK. 


\section{JOB DESCRIPTION ANALYSIS}

Employers have been found to require a broader set of skills over time and these skills are no longer closely related to the occupation [10], rather to social and personal characteristics. It has also been found that employers require a wide range of skills, even for low-skilled occupations as well as for new and possibly high-skilled occupations [11].

While examining job advertisements, it was found that employers tend to focus on company branding instead of skills they require from candidates. This must be taken into consideration during analysis and presentation of the results.

Types of words have a major role in understanding the required skills of the employees. Research performed by Seljan [33] shows that verbs are usually used for describing duties, they create multi-word units consisting of verb phrases (VPs), which appear less frequently than noun phrases (NPs). NPs (noun preceded by adjective or noun) appear the most frequently carrying the meaning of the sentence, in the domain of law, or when extracting terminology using language-independent methods in the medical domain using the statistical and hybrid approach for information retrieval purposes [34].

While examining gathered job descriptions, it was found that the types of words employers use in the Job Description section can reflect whether employers focus on the duties of the candidates, or they prefer to list the required skills. As it was mentioned before, employers who use the Job Description section for branding companies must be taken into consideration. For the analysis, the first step was removing stop words to shorten the processing time. The next step was tokenizing the words and categorizing them by type.

The share of word types in job advertisements for the USA is given as follows; adjectives 8,8 \%, verbs $8,9 \%$, nouns $38,5 \%$, other $43,8 \%$. The UK has a very similar division of the shares of word types to that of the USA; adjectives $8,3 \%$, verbs $9,3 \%$, nouns $35,1 \%$, other $47,3 \%$. Verbs are usually used for describing the duties of employees or for describing what does the company does. The share of adjectives that is almost like the share of verbs might suggest a growing trend of describing demanded skills. The share of word types in job advertisements for Dublin is given as follows; adjectives 8,8 \%, verbs 8,2 \%, nouns 35,5\%, other 47,5\%, while for Hong Kong is: adjectives $8,4 \%$, verbs $7,3 \%$, nouns $39,4 \%$, other $44,8 \%$. The share of adjectives is bigger than the share of verbs. The reason for this might be that employers are more focused on the skills they require from the candidates.

Skills analysis is based on the competence model 'KODE' [35], that is competencies are divided into four fields: Personal competence $(\mathrm{P})$, Decision-making and responsibility (A), Professional and methodical competence (F), and Social and communicative skills (S). Each field consists of four blocks and each block contains four competencies. The results are shown in Table 2 as percentages of job advertisements in which competencies from the category appear.

The first aspect to point out is that three out of four observed countries and cities have the largest share of social and communicative skills represented in the job advertisements. This

Table 2. Skills by categories found in job advertisements

\begin{tabular}{|l|r|r|r|c|}
\hline \multicolumn{1}{|c|}{ Skills } & USA & UK & \multicolumn{1}{c|}{$\begin{array}{c}\text { Hong } \\
\text { Kong }\end{array}$} & Dublin \\
\hline Personal Competence (P) & 11694 & 9077 & 11781 & 9681 \\
\hline Social and communicative skills (S) & 35534 & 13649 & 4521 & 9980 \\
\hline Decision-making and responsibility (A) & 4426 & 5206 & 4521 & 5589 \\
\hline Professional and methodical competence (F) & 12476 & 9009 & 4110 & 8383 \\
\hline
\end{tabular}


confirms the outcomes of the study conducted by Dörfler and Werfhorst [10]. According to the Indeed career guide, skills such as verbal and written communication, teamwork skills and problem-solving skills, are ultimate skills that are demanded no matter occupation.

The results of the analysis shown above confirm that these skills are extremely important to employers. In addition, there is also a high demand for candidates who are customer-oriented and who possess conflict handling skills as well as language skills. All of this points to the conclusion that employers are looking for candidates who have solid relationship management skills and who work great with both clients and other employees.

The second most represented category is personal competence. For Hong Kong, it is the most represented category. As it is desired to have excellent interpersonal skills, according to employers, having excellent self-management skills is important as well. Motivation is a highly sought-after competency, which indicates that employers look for candidates who are focused on their professional growth. Responsibility, flexibility, and willingness to learn stand out as the highly represented competencies in this category. Employers also cite self-discipline, credibility, and reliability as desirable skills from this category. This highlights the fact that employers seek individuals they can rely on.

It is interesting that professional and methodical competence is the third most represented category. However, skills that stand out in this category as the most required are time-management skills and organisational skills. Employers highlight that employee must be able to complete tasks in a timely manner. Work ethic is also found as highly demanded by employers. Attention to detail and presentation skills are mentioned by many employers as highly desirable skills. From occupation-related skills in this category most required are analytical skills, products knowledge, and project management. It should be noted that this category is the least represented category in Hong Kong.

Finally, the last category is decision-making and responsibility. Although this category is the least represented, there are several sub-categories that are found highly demanded such as leadership skills and stress handling skills. Enthusiastic and results-driven candidates are found to be desirable to employers as well. This indicates that employers seek positive individuals as the energy of an individual can affect the entire team. In conclusion, the proportion of ads that have keywords associated with the skills categories reflects the relative importance of these skills for employers [21].

Numerous occupations require a certain level of education to be eligible to work in that profession. For example, New York, Miami, and Washington are cities with the highest percentages of occupations requiring a degree. As expected, the highest demand is for a bachelor's degree. However, most job advertisements do not require any degree. On the other hand, low percentages for the UK indicate that employers in the UK usually do not state the level of education they require or most occupations in job advertisements do not require a degree. It is the same case with Hong Kong as well.

Regarding salaries, the job advertisements which provide information about the salary are in the minority. Job advertisements from Dublin and Hong Kong did not provide enough information about the salaries. It was found only that the job of an administrative assistant is usually better paid in the USA with the average salary in the range from $\$ 40000$ to $\$ 60000$ while in the UK average salary for an administrative assistant is in the range from $\$ 20000$ to $\$ 30000$. According to one source which examines the salaries of the jobs in the USA, the median salary for the job of service representative in 2018 was $\$ 33750$. 


\section{DISCUSSION}

The development of science and technology brought new ways of advertising job vacancies [9]. Advertising job vacancies is nowadays possible at a much lower cost [21]. This allows employers to write very detailed job advertisements with much more requirements and therefore it is getting harder for individuals to remain competent.

The content analysis proved to be a very efficient method in extracting meaningful information from job advertisements or any text in general [19]. The content analysis implemented and presented in this study derived useful insight into the employment trends for the USA, UK, Dublin, and Hong Kong. Useful conclusions were given about the skills that employers require, which are subject to constant changes.

From the results of this study, it is safe to conclude that there is a growing demand for social and personal skills than for professional and decision-making skills. Communication and organizational skills, strong work ethic, ability to adapt, motivation, and time-management skills proved to be essential skills employers require regardless of the industry or occupation. The analysis yielded occupations from the administration and service providing sector as the most demanded occupations in all analysed countries and cities. However, the share of occupations from other sectors in the job advertisements differs from city to city.

Although the results of the content analysis showed similar trends in the UK and the USA, the difference in skills demands between these countries exists. Only skills from the decision-making and responsibility category are equally demanded across these countries. A similar trend is noted in the case of Dublin and Hong Kong. However, it is also noted that skills from personal competence are equally demanded across these cities. There are several possible reasons for these results. Employers across different countries and cities might have different priorities when writing job descriptions. They can be focused on listing duties which candidates will perform or they can focus on the skills that candidates must possess. Also, there are employers who focus on promoting their company rather than requirements. The results also depend on the representation of the occupations since different occupations require different categories of skills. For example, occupations from the retail sector will probably require more social and communicative skills than occupations from the IT sector which will require more professional and methodical skills.

Another conclusion that emerged from the analysis is that employers find it crucial for candidates to have developed interpersonal skills. Equally important is to have excellent self-management skills meaning that the candidate must be motivated, willing to learn and grow in a professional way. All that points to the conclusion that employers are usually not focused on occupationrelated skills. However, it is important to mention that this does not mean that occupationrelated skills are not represented at all in the job advertisements. Occupation-related skills are demanded as well, although to a lesser extent.

The analysis of the employers showed that it depends on country to country which types of employers use online recruitment websites as a way of filling job vacancies. For instance, public sector bodies in the UK use recruitment websites unlike public sector bodies in Hong Kong. Finally, the analysis of the salaries gave insight into how salary for the same occupation differs from country to country or from city to city.

There are certain limitations of this study related to the quality, reliability, and representativeness of data from online job advertisements. These issues must be taken in consideration when using this kind of source as research data. For example, uncontrollable variables, like the quality of writing in job advertisements, can affect research [22]. In addition, the description of the job depends on recruiters' ability to communicate through written language [23]. Therefore, job 
advertisements can possibly be ambiguous and hard to analyse. This also leads to challenges in coding this kind of problem. Furthermore, job advertisements usually reflect an ideal future state rather than the current reality of the labour market. The current demand on the labour market reflects development in a particular sector and does not necessarily represent the existing structure of the labour market. IT sector is the most suitable example to illustrate this point. IT sector has recently expanded and as a result, many countries record an increase in job vacancies in an IT industry. However, this does not necessarily reflect the actual share of the IT industry in a national structure of employers or employees [11].

Another challenge also occurs while using online job advertisements as a data source. Difficulties might occur while ascertaining whether the set of online job vacancies is a representative sample of all job vacancies in a specified economy. An example of this is international firms which usually first employ internally available candidates before announcing a vacancy in a labour market. In addition, in smaller towns or villages there are closer relations between populations, which often means that jobs are first offered to candidates known personally to the employer. This leads to the conclusion that jobs can be differently distributed and a part of them does not require a formal 'vacancy' announcement. This also indicates that online job advertisements can provide insight into what types of jobs employers find difficult to fulfil through internal or informal ways of finding candidates [11].

Thus, using job advertisements from an established portal and interpreting the results with caution can be a valid and acceptable choice. In addition, despite the previously mentioned limitations of job advertisements as research data, research using this source has been published in leading social science journals, suggesting that the field is expanding. Moreover, with the spreading of the Internet, reliance on Internet-based recruitment will possibly increase [9].

Another limitation of this study relates to the content analysis method itself. Although this is a very convenient method and it has numerous advantages for this kind of research, it has some disadvantages as well. The advantage of the human reading of job advertisements is that it may ensure that words are analysed in terms of their context as well as their frequency. Another disadvantage is that manual coding of an extensive data set is time-consuming. This may lead to the problem of biased or inconsistent coding, particularly if data are not cross-coded effectively.

Thus, future research might include more sophisticated methods applied in the domain of natural language processing, such as deep learning or other machine learning algorithms to extract meaningful patterns from the data. In addition, future avenues of this research might consist of a more detailed interpretation of the results represented in this article, e.g., further analysis could be also performed on the same data sample used in this article to derive additional conclusions.

Overall, our findings have several implications for job advertising strategists and can help marketers and managers understand how to structure communication content in such a way that it avoids common problems such as mismatch in terminology between requirements of industry and offer of educational and training institutions, etc. Managers can be guided by this research in deciding which characteristics of content to promote to elicit favourable responses among potential employees. Moreover, the outcomes of this research study can be used for improving curricula, training, and performance management.

\section{REFERENCES}

[1] Harper, R.: The collection and analysis of job advertisements: A review of research methodology.

Library and Information Research 36(112), 29-54, 2012,

http://dx.doi.org/10.29173/lirg499, 
[2] Maier, J.L.; Greer, T. and Clark, W.J.: The management information systems (MIS) job market late 1970s-late 1990s.

Journal of Computer Information Systems 42(4), 44-49, 2002,

[3] Gardiner, A; Aasheim, C.; Rutner, P. and Williams, S.: Skill Requirements in Big Data: A Content Analysis of Job Advertisements.

Journal of Computer Information Systems 58(3), 1-11, 2017,

http://dx.doi.org/10.1080/08874417.2017.1289354,

[4] Backhaus, K.: An Exploration of Corporate Recruitment Descriptions on Monster.com.

Journal of Business Communication 41(2), 115-136, 2004,

http://dx.doi.org/ 10.1177/0021943603259585,

[5] Baravalle, A. and Capiluppi, A.: It jobs in UK: Current trends.

Proceedings of the $3^{\text {rd }}$ IEEE International Conference on Computer Science and Information Technology (IEEE ICCSIT), Chengdu, July 2010,

[6] Smith, D. and Ali, A.: Analyzing computer programming job trend using web data mining.

Issues in Informing Science and Information Technology 11, 203-214, 2014,

http://dx.doi.org/10.28945/1989,

[7] Surakka, S.: Analysis of Technical Skills in Job Advertisements Targeted at Software Developers.

Informatics in Education 4(1), 101-122, 2005,

http://dx.doi.org/10.15388/infedu.2005.07,

[8] Molinero, C. and Xie, A.: What do UK employers want from OR/MS?

Journal of The Operational Research Society 58(12), 1543-1553, 2007,

http://dx.doi.org/10.1057/palgrave.jors.2602286,

[9] Lee, S. and Lee, C.: IT managers' requisite skills.

Communications of the ACM 49(4), 111-114, 2006,

http://dx.doi.org/10.1145/1121949.1121974,

[10] Dörfler, L. and Werfhorst, H.: Employers' demand for qualifications and skills.

European Societies 11(5), 697-721, 2009,

http://dx.doi.org/10.1080/14616690802474374,

[11] Kureková, L.M.; Beblavý, M. and Thum-Thysen, A.: Using online vacancies and web surveys to analyse the labour market: a methodological inquiry.

IZA Journal of Labor Economics 4(1), 2015, http://dx.doi.org/10.1186/s40172-015-0034-4,

[12] Pejić Bach, M.; Bertoncel, T.; Meško, M. and Krstić, Ž.: Text mining of industry 4.0 job advertisements.

International journal of information management 50, 416-431, 2020, http://dx.doi.org/10.1016/j.ijinfomgt.2019.07.014,

[13] Bennett, R.: Employers' Demands for Personal Transferable Skills in Graduates: a content analysis of 1000 job advertisements and an associated empirical study.

Journal of Vocational Education \& Training 54(4), 457-476, 2002, http://dx.doi.org/10.1080/13636820200200209,

[14] Wade, M.R. and Parent, M.: Relationships between job skills and performance: a study of webmasters.

Journal of Management Information Systems 18(3), 71-96, 2001, http://dx.doi.org/10.1080/07421222.2002.11045694,

[15] Huang, H.; Kvasny, L.; Joshi, K.D.; Trauth, E.M. and Mahar, J.: Synthesizing IT job skills identified in academic studies, practitioner publications and job ads.

Proceedings of the special interest group on management information system's $47^{\text {th }}$ annual conference on Computer personnel research, ACM, Limerick, 2009,

[16] Iyer, H.: A profession in transition: towards development and implementation of standards for visual resources management. Part A - the organization's perspective.

Information Research 14(3), 2009, 
[17] Payne, H.: Information management: a contemporary study of the discipline and the profession. Master's Thesis.

Economic and Social Studies, Aberystwyth University, Penglais, 2009,

[18] Reeves, R. and Hahn, T.: Job Advertisements for Recent Graduates: Advising, Curriculum, and Job-seeking Implications.

Journal of Education for Library and Information Science 51(2), 103-119, 2010,

[19] Krstić, Ž.; Seljan, S., and Zoroja, J.: Visualization of Big Data Text Analytics in Financial Industry: A Case Study of Topic Extraction for Italian Banks.

ENTRENOVA - ENTerprise REsearch InNOVAtion 5(1), 35-43, 2019,

[20] Wikipedia contributors: Indeed.

Wikipedia, The Free Encyclopedia,

http://en. wikipedia.org/w/index.php?title=Indeed\&oldid=958828080, accessed $8^{\text {th }}$ May 2020,

[21] Sodhi, M. and Son, B.G.: Content analysis of OR job advertisements to infer required skills. Journal of the Operational Research Society 61(9), 1315-1327, 2010, http://dx.doi.org/10.2139/ssrn.1640814,

[22] Xu, H.: The Impact of Automation on Job Requirements and Qualifications for Catalogers and Reference Librarians in Academic Libraries.

Library Resources \& Technical Services 40(1), 9-31, 1996, http://dx.doi.org/10.5860//rts.40n1.9,

[23] Ahmed, S.: Desired competencies and job duties of non-profit CEOs in relation to the current challenges: Through the lens of CEOs' job advertisements.

Journal of Management Development 24(10), 913-928, 2005, http://dx.doi.org/10.1108/02621710510627055,

[24] -: Content analysis.

http://en.wikipedia.org/wiki/Content analysis, accessed $8^{\text {th }}$ May 2020,

[25] Pejić Bach, M.; Krstić, Ž.; Seljan, S. and Turulja, L.: Text mining for big data analysis in financial sector: A literature review.

Sustainability 11(5), No. 1277, 2019,

http://dx.doi.org/10.3390/su11051277,

[26] Ćurlin, T.; Jaković, B. and Miloloža, I.: Twitter usage in tourism: a literature review. Business Systems Research 10(1), 102-119, 2019, http://dx.doi.org/10.2478/bsrj-2019-0008,

[27] -: Natural Language Toolkit.

http://en.wikipedia.org/w/index.php?title=Natural_Language_Toolkit\&oldid=951031114, accessed $27^{\text {th }}$ May 2020 ,

[28] -: NumPy. http://en. wikipedia.org/w/index.php?title $=$ NumPy\&oldid $=958607142$, accessed $28^{\text {th }}$ May 2020,

[29] Office for National Statistics: Vacancies by industry. http://www.ons.gov.uk/employmentandlabourmarket/peoplenotinwork/unemployment/datasets/va canciesbyindustryvacs 02 , accessed $28^{\text {th }}$ May 2020 ,

[30] Greater London Authority: London labour market projections 2016. GLA Economic, London, 2016,

[31] Nugent, C.: Labour Market Trends in the Republic of Ireland (2019). Nevin Economic Research Institute (NERI), 2019, http://dx.doi.org/10.4324/9781315792521-2,

[32] Office of Occupational Statistics and Employment Projections: Employment Projections: 2018-2028 Summary.

US Bureau of Labor Statistics, Washington, 2019, http://www.bls.gov/news.release/ecopro.nr0.htm, accessed $28^{\text {th }}$ May 2020,

[33] Seljan, S. et al.: Comparative Analysis of Automatic Term and Collocation Extraction. INFuture 2009: Digital resources and knowledge sharing, pp.219-228, 2009, http://infoz.ffzg.hr/INFuture/2009/papers/INFuture2009.pdf, accessed $28^{\text {th }}$ May 2020, 
[34] Seljan, S.; Baretić, M. and Kučiš, V.: Information Retrieval and Terminology Extraction in Online Resources for Patients with Diabetes.

Collegium Antropologicum 38(2), 705-710, 2014,

[35] Heyse, V. and Erpenbeck, J.: Kompetenzmanagement-Methoden,Vorgehen, KODE® und KODE $囚 \mathrm{X}$ im Praxistet.

Waxmann Verlag GmbH, Münster, 2007. 